\title{
Sosialisasi Penggunaan Kabel Sesuai SNI Untuk Instalasi Listrik Rumah Tinggal Di Nagori Pagar Pinang Kecamatan Jorlang Hataran Kabupaten Simalungun
}

\section{Tambos August Sianturi, Jhon Sufriadi Purba, Winfrontstein Naibaho}

\author{
Teknik Mesin \\ Universitas HKBP Nommensen Pematangsiantar, Jl. Sangnawalu No. 4 \\ Pematangsiantar Sumatera Utara \\ Email: tambos.sianturi73@gmail.com
}

\begin{abstract}
Abstrak
Energi Listrik adalah energi yang dibangkitkan dari generator kemudian disalurkan melalui Transmisi dan Gardu induk, kemudian disalurkan melalui jaringan Distribusi dan sampai ke konsumen rumah tinggal perkantoran, maupun industri. Tegangan yang di distribuskan sampai ke rumah tangga dengan tegangan yang diterima berkisar 220 Volt, dengan instalasi rumah tangga yang terpasangan beberapa peralatan rumah tangga. Instalasi listrik rumah tinggal yang baik terdiri dari sakelar dan stop kontak yang terhubung ke peralatan listrik. Instalasi listrik rumah tangga terdiri dari KWH meter, MCB, Sakelar peralatan rumah tangga (lampu, pompa) dan Stop Kontak.
\end{abstract}

Kata Kunci: Energi Listrik, Tegangan, Instalasi

\section{Pendahuluan}

Salah satu cara untuk menghindari bahaya listrik adalah dengan iinstalasi listrik rumah yang baik dan aman. Umunya jumlah orang yang mampu untuk memasang instalasi listrik sangat kurang. Proses instalasi listrik bias dikatakan cukup sederhana,sehingga dapat dilakukan orang tanpa latar belakang pendidikan khusus. Namun ada aspek-aspek yang perlu diketahui masyarakat dalam instalasi listrik, sehingga bias menghasilkan instalasi yang baik dan aman (Joewono 2014).

Menurut Mr. David Latimer; Chairman IEC-TC 64 dalam ceramahnya di BSN beberapa tahun yang lalu, Beliau menerangkan bahwa di negaranya U. K. dan pasti juga di negara-negara yang lain, pada umumnya dinas kebakaran tidak mempunyai pengalaman dalam bidang kelistrikan, dan meskipun tidak ada tanda bekas sisa-sisa aktivitas listrik dalam rongsokan (wreckage), bila tidak ada bukti yang nyata dan cepat, terjadinya kebakaran dianggap penyebabnya karena akibat listrik. Risiko akibat pemakaian listrik diperkenalkan dalam IEC30364 Electrical Installations in Buildings instalasi listrik untuk bangunan. Kebakaran menyebabkan kehilangan nyawa dan tak hanya meliputi seseorang saja, tetapi dapat terjadi di tempat-tempat dimana banyak manusia berkumpul, seperti pabrik, pusat perbelanjaan, pemukiman penduduk dsb.nya. Selain kehilangan nyawa manusia juga mengakibatkan kerugian besar dalam hal materi. Sebetulnya untuk mendapat kepastian apa penyebab utama dari kebakaran sering kali sangat sulit. Biasanya bukti yang nyata telah dimusnahkan oleh api, dan tambahan pula kerusakan yang disebabkan pada instalasi listrik karena api sering ditujukan ke busur api (arcing) antara konduktor, karena kerusakan isolasi, dengan demikian diambil kesimpulan yang tentunya salah besar, bahwa terjadinya kebakaran asal mulanya dari listrik

\subsection{Tujuan Kegiatan}

Adapun tujuan kegiatan yang ingin dicapai pada kegiatan pelaksanaan Pengabdian pada masyarakat ini adalah :

a) Memberikan bekal pengetahuan mengenai teori secara dasar mengenai arti talasi rumah tinggal 
b) Dapat memberikan bekal ketrampilan bagaimana cara pemasangan instalasi penerangan rumah tinggal.

c) Sebagai wujud rasa kepeduliaan kepada lembaga perguruan tinggi, sehingga dapat memberdayakan masyarakat pedesaan.

d) Menentukan jenis Kabel untuk instalasi listrik rumah tinggal

e) Menentukan ukuran Kabel Penghantar sesuai dengan kemampuan Hantar Listrik.

\subsection{Manfaat Kegiatan}

Manfaat dari pemilihan kabel SNI (Standart Nasional Indonesia) sesuai dengan kebutuhan untuk instalasi peralatan listrik rumah tinggal :

a) Masyarakat dapat wawasan lebih lagi tentang listrik.

b) Dapat memilih kabel sesuai dengan kebutuhan peralatan disesuaikan dengan kemampuan kabel

c) Dapat mengurangi resiko kehilangan beban (over load) sehingga kabel dapat mudah panas dan terjadi korseleting listrik

d) Arus beban peralatan yang terhubung ke kabel SNI diupayakan pemakaian maksimum $60 \%$ dari kemampuan kabel yang terpasang.

e) Saran kami agar kabel yang terpasang di instalasi rumah dengan kabel 2,5 $\mathrm{mm}$ dengan kemampuan 26 Ampere, dengan harapan arus yang terpakai hanya $60 \%$ dari kemampuan kabel tersebut

\section{Realisasi Kegiatan}

\subsection{Bentuk Kegiatan dan jadwal serta Tempat kegiatan}

\section{a. Metode Pelaksanaan Kegiatan}

Tim Pengabdian Kepada Masyarakat telah melakukan kegiatan sebagai berikut :

1. Memberikan ceramah kepada masyarakat konsep instalasi kelistrikan yang baik dan benar sesuai PUIL 2011.

2. Memperagakan alat peraga instalasi listrik sehingga anggota masyarakat bisa menyaksikannya secara langsung instalasi listrik yang benar, cara penyambungan kabel, pemasangan isolasi, dan lain-lain.

3. Memberikan/memasang instalasi listrik di fasilitas umum sebagai contoh instalasi listrik yang benar kepada masyarakat.

4. Pemasangan stiker-stiker tentang hemat energi ke rumah-rumah penduduk dan fasilitas umum serta cara-cara pengoperasian peralatan rumah tangga yang dicatu oleh daya listrik agar masyarakat dapat menghemat energi listrik dan pemasangan stiker penggunaan stop kontak yang benar dan stop kontak yang salah agar terhindar dari bahaya kebakaran.

5. Mengadakan diskusi dengan masyarakat baik pada saat diadakan sosialisasi maupun pada saat pemasangan stiker.

6. Melakukan evaluasi ke desa hasil sosialisasi yang telah dilakukan.

b. Waktu Efektif Pelaksanaan Kegiatan

Kegiatan Pelaksanaan Pengabdian Kepada Masyarakat ini akan dilaksanakan pada Tanggal 10 s.d 16 Februari 2020 dengan rincian sebagai berikut:

Tabel 1. Jadwal Pelaksanaan

\begin{tabular}{|c|c|c|c|c|c|c|c|c|}
\hline \multirow[t]{2}{*}{ NO } & \multirow[t]{2}{*}{ Kegiatan } & \multicolumn{4}{|c|}{$\begin{array}{c}\text { Jadwal Pelaksanaan } \\
\text { Tanggal : }\end{array}$} & \multirow[b]{2}{*}{14} & \multirow[b]{2}{*}{15} & \multirow[b]{2}{*}{16} \\
\hline & & 10 & 11 & 12 & 13 & & & \\
\hline 1 & Persiapan Peralatan & & & & & & & \\
\hline 2 & $\begin{array}{l}\text { Pengantaran Materi } \\
\text { Presentasi Materi }\end{array}$ & & & & & & & \\
\hline 3 & Test/Latihan & & & & & & & \\
\hline
\end{tabular}

\section{c. Tempat Kegiatan}


Tempat pelaksanaan pengabdian kepada masyarakat ini beralamat: Di Nagori Pagar Pinang Kecamatan Jorlang Hataran Kabupaten Simalungun Sumatera Utara

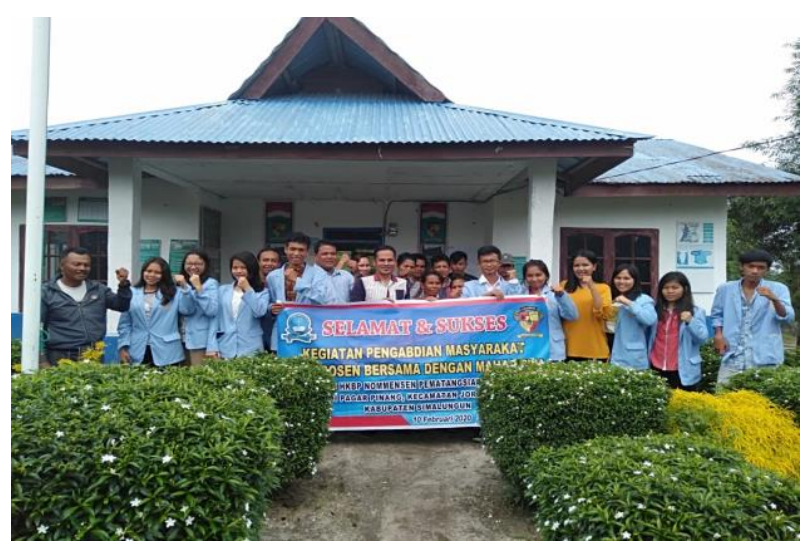

Gambar 1. Lokasi Pengabdian Pada Masyarakat

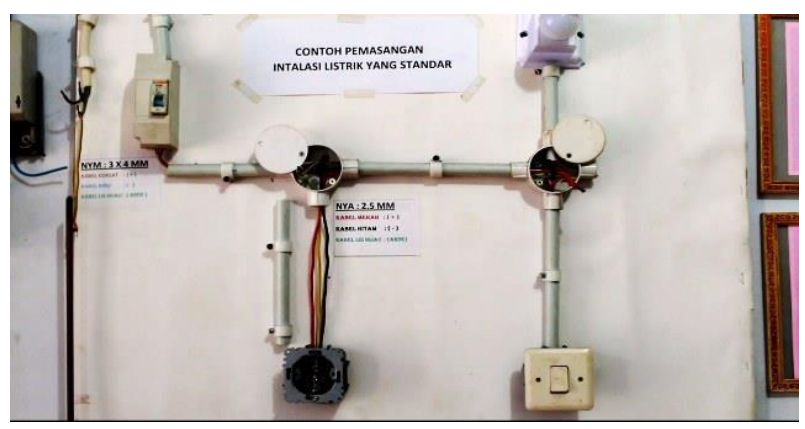

Gambar 2. Penggunaan Listrik yang baik

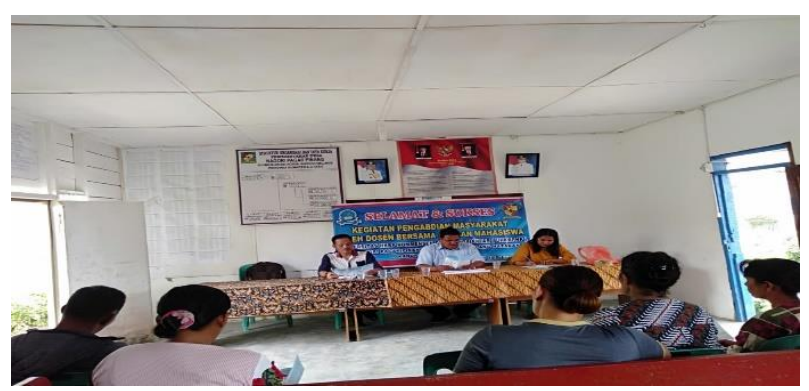




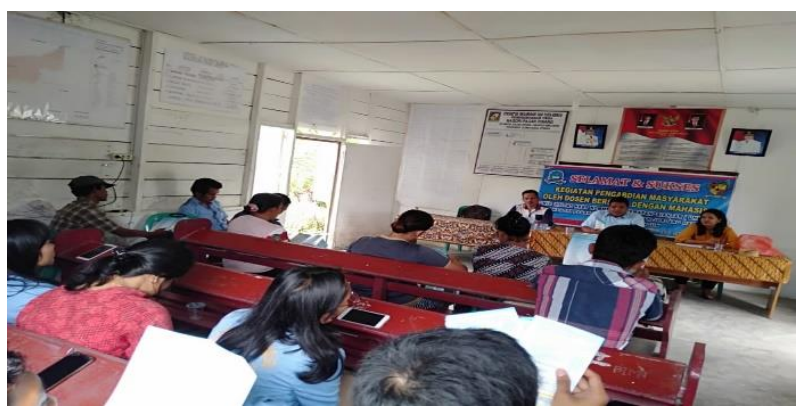

Gambar 3. Pemaparan materi tentang Penggunaan Kabel sesuai SNI untuk Instalasi Listrik Rumah

\subsection{Tim Pelaksana Pengambdian Pada Masyarakat}

Tabel 2. Susunan Tim Pengabdian

\begin{tabular}{|c|l|l|l|}
\hline No & Nama & Peran danam Tim & Pekerjaan \\
\hline 1 & Tambos August Sianturi, ST., MT & Ketua & Dosen \\
\hline 2 & Jhon Sufriadi Purba, SPd., MT & Sekretaris & Dosen \\
\hline 3 & Winfronstein Naibaho, ST., MT & Anggota & Dosen \\
\hline
\end{tabular}

\section{Tinjauan Hasil yang Dicapai}

a. Beberapa masyarakat mampu dan memahami memasang instalasi penerangan luar yang dipasang di depan rumah atau teras rumah

b. Masyarakat mengetahui pemeliharaan instalasi listrik yang benar dan memahami umur instalasi yang sesuai standar.

c. Beberapa masyarakat memahami kondisi instalasi listrik rumahnya yang telah lewat dari standar yang diijinkan oleh PUIL 2011, sehingga masyarakat sudah menyiapkan diri untuk merenovasi instalasi listriknya untuk menghindari bahaya kebakaran akibat instalasi listrik yang sudah rusak.

d. Masyarakat mampu melakukan penghematan energi dengan mengoperasikan beberapa peralatan elektronik rumah tangga seperti Magic Jar, kulkas dan lain-lain sesuai kebutuhan dan waktu yang tepat.

e. Masyarakat diberikan batasan-batasan dan jenis-jenis kabel yang boleh dipergunakan.

f. Masyarakat sudah mendapatkan sosialisasi dalam bentuk ceramah dan menyaksikan demontrasi dengan alat peraga instalasi listrik yang benar dan jenis-jenis kabel yang sesuai standar.

g. Masyarakat ikut serta menyaksikan pemasangan instalasi luar yang dipasang di Taman rumah.

h. Masyarakat mampu mengoperasikan peralatan elektronik rumah tangga dengan efisien sehingga dapat menghemat energi.

i. Masyarakat bersama-sama memasang stiker-stiker hemat energi dan penggunaan stop kontak yang benar di rumah-rumah penduduk dan fasilitas umum sebagai upaya mengajak masyarakat untuk hemat energi dan menggunakan instalasi listrik sesuai standar.

\section{Daftar Pustaka}

2011. Persyaratan Umum Instalasi Listrik ( PUIL 2011). Jakarta

Budiman, M. Dkk. 2000. Panduan Instalasi Listrik Untuk Rumah Berdasarkan PUIL 2000. Jakarta : Yayasan

Usaha Penunjang Tenaga Listrik Bekerja sama dengan Copper Development Centre. South East Asia.

Handoko, P. 2000. Pemasangan Instalasi Listrik Dasar. Yogyakarta : Kanisius.

Harten, PV. Terjemahan : Setiawan E. 1991. Instalasi Listrik Arus Kuat 1. Bandung : Bina Cipta. 
Harten, PV. Terjemahan : Setiawan E. 1991. Instalasi Listrik Arus Kuat 2. Bandung : Bina Cipta. Harten, PV. Terjemahan : Setiawan E. 1991. Instalasi Listrik Arus Kuat 3. Bandung : Bina Cipta.

\section{SK Pelaksanaan Pengabdian}

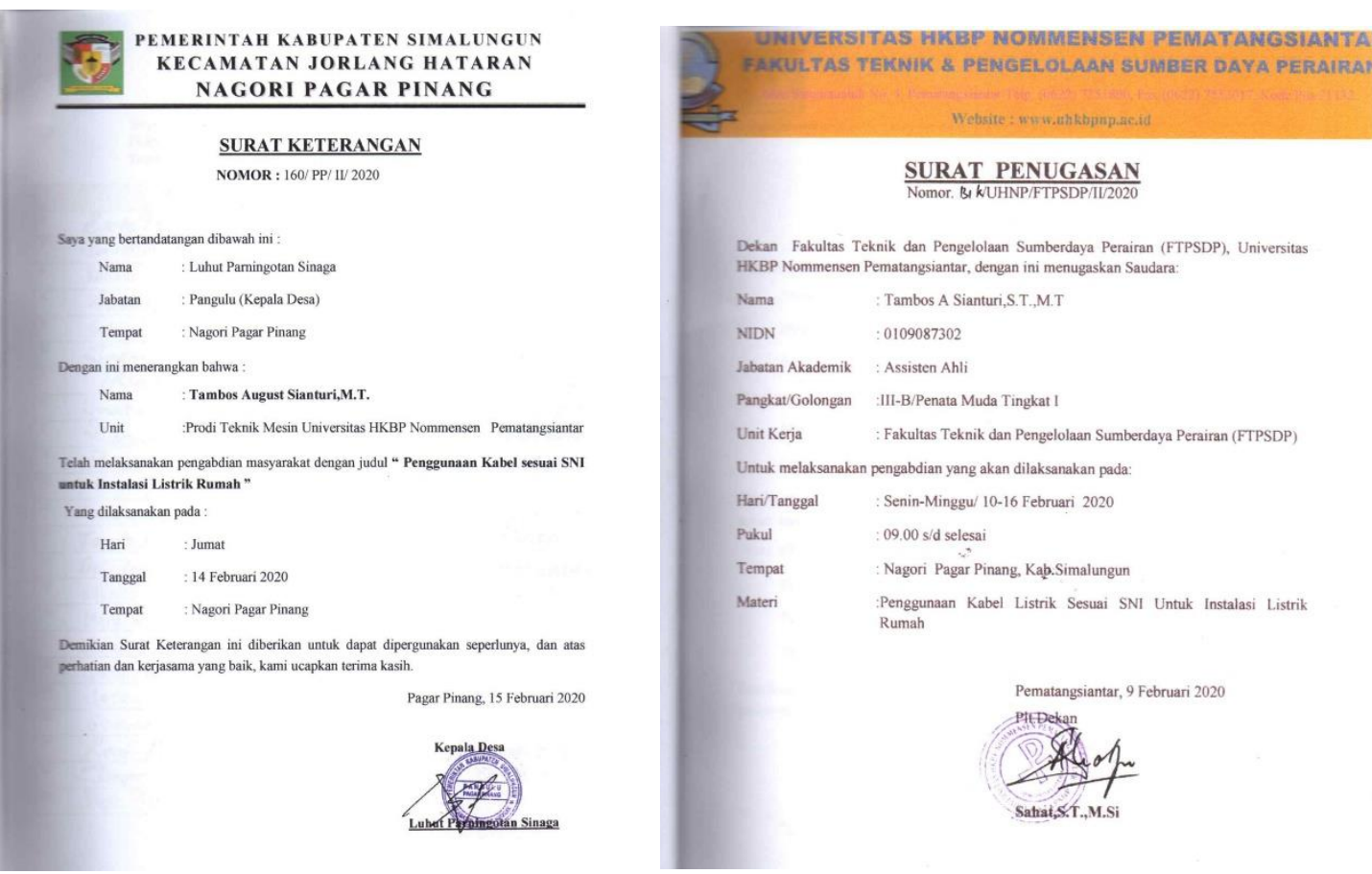

6. Dastar Hadir

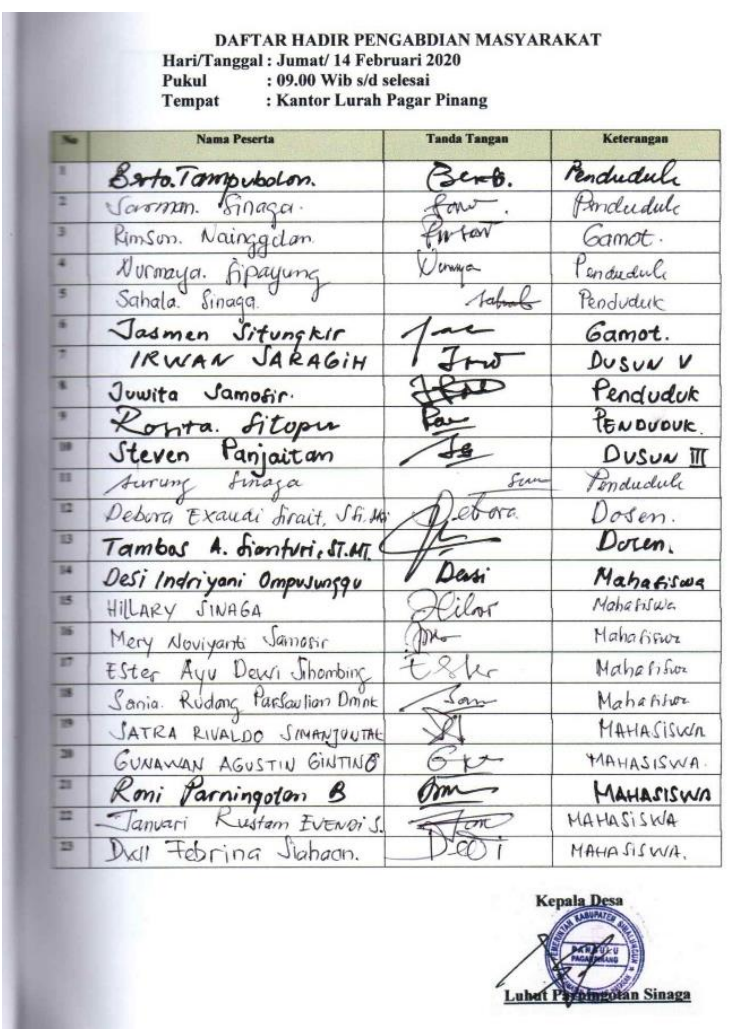

